\title{
Optimization of Heat Recovery for Shell \& Tube Exchangers in Sulphur Granulation Unit of South Pars Fifth Refinery by Software, ASPEN B-JAC
}

\author{
Kazem Moaveni", Mehran Zarkesh \\ Department of Mechanic, Dashtestan Branch, Islamic Azad University, Borazjan, Iran \\ Email address: \\ kazemmoaveni@gmail.com (K. Moaveni) \\ ${ }^{*}$ Corresponding author
}

\section{To cite this article:}

Kazem Moaveni, Mehran Zarkesh. Optimization of Heat Recovery for Shell \& Tube Exchangers in Sulphur Granulation Unit of South Pars Fifth Refinery by Software, ASPEN B-JAC. American Journal of Mechanical and Industrial Engineering. Vol. 2, No. 4, 2017, pp. 162-173. doi: 10.11648/j.ajmie.20170204.12

Received: April 28, 2017; Accepted: May 6, 2017; Published: July 5, 2017

\begin{abstract}
Shell and tube heat exchangers are the most important tools in heat transfer process. Optimization efficiency of these tools is always the goal of designers. Now a day there are a lot of efficient methods for selecting the best heat exchanger, such as analytic and numerical methods that everyone has advantages and defects. For example, confront of jamming in calculations by receiving to the local minimums and errors during interruption quantities. Today by entering of simulation and design softwares in industries, the simulation of process tools is so simple. the procedure of studies in this thesis is in these steps: first simulation of sulfur solidification heat exchangers in ASPEN B-JAC software same as operation conditions and then evaluation the effects of changing the design parameters in tube bundle section such as number of passes, arrangement of tubes, number of baffles,.... the sulfur solidification package' heat exchanger that it's active fluid is demine water for cooling of package will be optimized till the rate of exchanged heat increases to 15 percent and pressure drop will not affect the operation conditions. The most important note in the correction of tube bundle is that the heat exchanger should be out of service and stopping of production, on the other hand changing in shell of heat exchanger needs to change the piping system and redesign of supports that will spend a lot of time for shut down of plant, so it is out of order for this thesis and optimization of tube bundle will be done.
\end{abstract}

Keywords: Optimization, Heat Recovery, Shell and Tube Exchanger, Sulphur Granulation, ASPEN B-JAC

\section{Introduction}

Natural gas is the most important source of energy with characteristics such as cleanliness and cheapness that make it more important. Increasing speed in converting gas to the fuel consumption in petrochemical industry, transportation industry and most importantly the cost of urban gas has made it one of the most important determining factor in the country's energy. The effectiveness and efficiency of refinery units is therefore of great importance to increase production. The aim of this study is to assess the possibility of reducing energy consumption in the South Pars gas refineries.

\section{The Governing Equations for the Design of Shell and Tube Exchanger}

\subsection{Calculated the Hrat Transfer and Pressure Drop in Shell Side by KERN}

\subsubsection{The Coefficient of Heat Transfer at the Shell Side}

The coefficient of heat transfer at the outer of the tubes bundle called The coefficient of heat transfer in shell side and The coefficient of heat transfer calculate based on the diameter $\mathrm{D}_{\mathrm{e}}$.

KERN suggested the following equation for calculate of heat transfer coefficient in the shell side: 


$$
\frac{\mathrm{h}_{\mathrm{o}} \mathrm{D}_{\mathrm{e}}}{\mathrm{k}}=0.36\left(\frac{\mathrm{D}_{\mathrm{e}} \mathrm{G}_{\mathrm{s}}}{\mu}\right)^{0.55}\left(\frac{\mathrm{c}_{\mathrm{p}} \mu}{\mathrm{k}}\right)^{\frac{1}{3}}\left(\frac{\mu_{\mathrm{b}}}{\mu_{\mathrm{w}}}\right)^{0.14}
$$

for

$$
2 X 10^{3}<\operatorname{Re}_{\mathrm{s}}=\frac{\mathrm{G}_{\mathrm{s}} \mathrm{D}_{\mathrm{e}}}{\mu}<1 X 10^{6}
$$

Where in $h_{O}$ is heat transfer coefficient in the shell side and $D_{e}$ is the diameter of the shell and $G_{S}$ is mass speed of shell side

The diameter of the shell is quadruple the pure surface of flow divided by the wetted perimeter that the pure surface of flow determined by tube locating on tube sheet (for locating with square pitchs and or triangular pitchs ).

$$
\mathrm{D}_{\mathrm{e}}=\frac{4 \mathrm{X} \text { surface area of free flow }}{\text { the wetted perimeter }}
$$

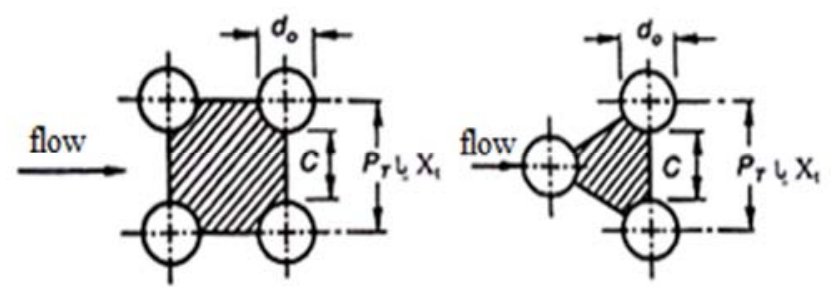

Figure 1. Locating of square pitch and triangular pitch of tube.

So, for square pitch, can be written:

$$
\mathrm{D}_{\mathrm{e}}=\frac{4\left(\mathrm{P}_{\mathrm{T}}^{2}-\frac{\pi \mathrm{d}_{\mathrm{o}}^{2}}{4}\right)}{\pi \mathrm{d}_{\mathrm{o}}}
$$

And for triangular pitch:

$$
\mathrm{D}_{\mathrm{e}}=\frac{4\left(\frac{\mathrm{P}_{\mathrm{T}}^{2} \sqrt{3}}{4}-\frac{\pi \mathrm{d}_{\mathrm{o}}^{2}}{8}\right)}{\frac{\pi \mathrm{d}_{\mathrm{o}}}{2}}
$$

In shell side, there is no free flow area which calculate mass speed in the shell side $G_{\mathrm{s}}$ in this reason amounts $G_{\mathrm{s}}$ can to be defined based on the level maximum of the hypothetical flow, that the distance between the tubes making in a row, in the diameter of the shell.

Variable that affect on the speed are shell diameter $D_{s}$, clearance $C$ between neighbor tubes, the pitch size $\mathrm{P}_{\mathrm{T}}$ and partition distance $\mathrm{B}$. width of flow level is in the rows of set tubes in shell center $\left(\mathrm{D}_{\mathrm{S}} / \mathrm{P}_{\mathrm{T}}\right) \mathrm{XC}$ and considered to be the length of flow level of wall distance $B$.

So, cross flow surface area with tube bundle, in the shell center $\mathrm{A}_{\mathrm{S}}$ is:

$$
A_{s}=\frac{D_{s}}{P_{T}}(C) \cdot B
$$

Where in $\mathrm{D}_{\mathrm{S}}$ is the inner diameter of the shell. so, flow mass speed in shell side is obtained the from following equation:

$$
\mathrm{G}_{\mathrm{s}}=\frac{\dot{\mathrm{m}}}{\mathrm{A}_{\mathrm{s}}}
$$

\subsubsection{Pressure Drop at the Shell Side}

Pressure drop at the shell side depends to number of tubes, times number of flow crossing from tube bundle between walls and the length each intersection. if suppose that divided the tube bundle length with 4 walls, as a result all fluid, 5 times will be in width of tube bundle with that the intersection.

By multiplying the distance in along vertical sheet on tube bundle, that can considered it to the inner diameter of the shell $\mathrm{D}_{\mathrm{S}}$ and number of times that flow cuts tube bundle, relationship is obtained for calculate of pressure drop in tube side.

The diameter for calculate of pressure drop is like The diameter for heat transfer. Pressure drop at the shell side is calculated with the following expression.

$$
\Delta \mathrm{P}_{\mathrm{s}}=\frac{\mathrm{fG}_{\mathrm{s}}^{2}\left(\mathrm{~N}_{\mathrm{b}}+1\right) \mathrm{D}_{\mathrm{s}}}{2 \rho \mathrm{D}_{\mathrm{e}} \phi_{\mathrm{s}}}
$$

That $\varnothing_{\mathrm{S}}=\left(\mu_{\mathrm{b}} / \mu_{\mathrm{W}}\right)^{0.14}{ }^{\prime} \mathrm{N}_{\mathrm{b}}$ is number of walls and $\left(\mathrm{N}_{\mathrm{b}}+1\right)$ is times number that flow in the shell, cut the tube bundle. the friction coefficient $\mathrm{f}$ calculate for shell from the following equation:

$$
f=\exp \left(0.576-0.19 \ln \operatorname{Re}_{\mathrm{s}}\right)
$$

Where in:

$$
400<\operatorname{Re}_{\mathrm{s}}=\frac{\mathrm{G}_{\mathrm{s}} \mathrm{D}_{\mathrm{e}}}{\mu} \leq 1 \mathrm{X} 10^{6}
$$

The gained friction coefficient is included, losses of flow entrance to shell and losses of flow output from the shell.

\subsubsection{Pressure Drop at the Tube Side}

Pressure drop in tube side, with having, number of tube passes $\mathrm{N}_{P}$ and the length of heat exchanger $\mathrm{L}$ is calculated.

Pressure drop for flow of tube side is calculated by the the following equation:

$$
\Delta \mathrm{P}_{\mathrm{r}}=4 N_{p} \frac{\rho U_{m}^{2}}{2}
$$

or

$$
\Delta \mathrm{P}_{\mathrm{t}}=4 \mathrm{f} \frac{\mathrm{LN}_{\mathrm{p}}}{\mathrm{d}_{\mathrm{i}}} \frac{\mathrm{G}_{\mathrm{t}}^{2}}{2 \rho}
$$

Changing direction in tube passes creates additional Pressure drop $\Delta \mathrm{p}_{\mathrm{r}}$ that is due sudden expansion and contraction that crossing fluid from tube will be during the back and needed for the per-pass tube be considered 4 times speed head.

So, total pressure drop in tube side is:

$$
\Delta \mathrm{P}_{\text {total }}=\left(4 \mathrm{f} \frac{\mathrm{LN}_{\mathrm{p}}}{\mathrm{d}_{\mathrm{i}}}+4 \mathrm{~N}_{\mathrm{p}}\right) \frac{\rho \mathrm{U}_{\mathrm{m}}^{2}}{2}
$$

\subsection{Bell - Delaware Method}

Analysis at the shell side is not as simple as analysis at tube side. The reason is that flow in the shell is complicated and the form is a combination of Cross flow, flow in the window of walls, by pass flow of the wall, and the flow in the shell and tube. This complicated pattern of flow is shown 
in figures 1 and 2.

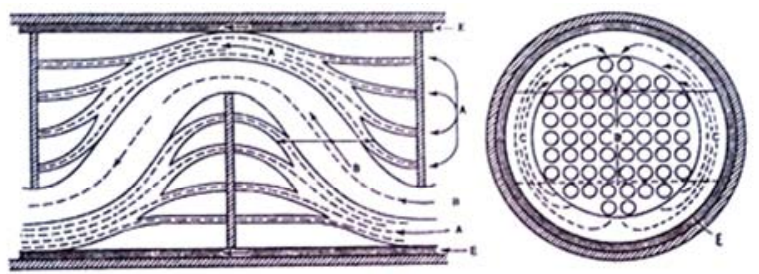

(A)

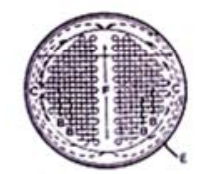

(B)

Figure 2. A) The diagram shows leakage paths for bypass flows of tube matrix including clearance leakages between walls, and shell and also between tube matrix and shell B) F flow for exchanging heat with two tube pass.

As shown in figure 1, 5 different flows are recognized. Flow $\mathrm{A}$ is the leakage in looseness between tubes and wall. Flow $\mathrm{B}$ is the cross main flow with the tube bundle. This favorable flow is at the shell side of heat exchanger. Flow $\mathrm{C}$ is the bypass flow of the tube bundle that is in flow in among the tube bundle between tubes outermost in the tube bundle and inner surface of the shell. Flow $\mathrm{E}$ is the leakage flow between the wall and shell that is in flow in the looseness between wall and the inner diameter of the shell.

Then there is flow F, that is current in every channel and used for making several tube pass in tube bundle lead. The above figure is an ideal figure of the above mentioned flows. The shown flows can be mixed and affect each other. A more completed mathematical analysis of the flow at shell side can take these issues into account.

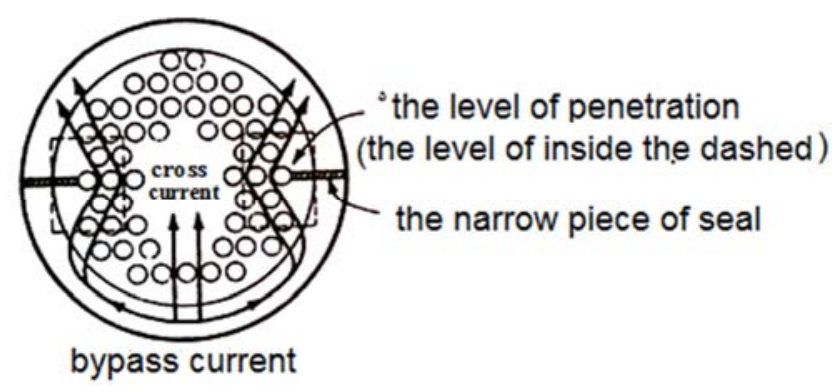

Figure 3. Design radial walls for decrease of bypass flow from looseness between shell and tube matrix.

A brief discussion is provided in this section that is about Bell - Delaware's method for analyzing the pressure drop and the coefficient for the heat transfer at the shell side.

\subsubsection{The Coefficient of Heat Transfer at the Shell Side}

The basic equation for the average calculating of coefficient of heat transfer at shell side is shown with the following relation

$$
h_{o}=h_{i d} J_{\ell} J_{b} J_{s} J_{r}
$$

in which $h_{i d}$ is the ideal of The coefficient of heat transfer for fully cross-flow with ideal tube bundle and is shown with the following relation:

$$
h_{i d}=j_{i d} c_{P s}\left(\frac{\dot{\mathrm{m}}}{\mathrm{A}_{\mathrm{s}}}\right)\left(\frac{\mathrm{k}_{\mathrm{s}}}{c_{\mathrm{ps}} \mu_{\mathrm{s}}}\right)^{\frac{2}{3}}\left(\frac{\mu_{\mathrm{s}}}{\mu_{\mathrm{s} \cdot \mathrm{w}}}\right)^{0.14}
$$

In which $\mathrm{j}_{\mathrm{id}}$ is the coefficient of $\mathrm{j}_{\text {id }}$ related to Colburn for a set of ideal tube, $\mathrm{S}$ is representative of the shell, and As is the cross flow surface area with the tubes at the shell center line between the two walls.

There are charts for determining $j_{\text {id }}$ as a function of Reynolds number at the shell side flow, $R_{S}=d_{0} \dot{m}_{S} / \mu_{S} A_{S}$, there are tube placement, And the size of pitch. such charts are represented in figures 3 to 5 .

As is calculated based on the equation 3

$$
A_{S}=\frac{D_{s}}{P_{T}}(C) . B
$$

Reynolds number is calculated based on the outer tube diameter and the minimum area of flow surface in the shell diameter.

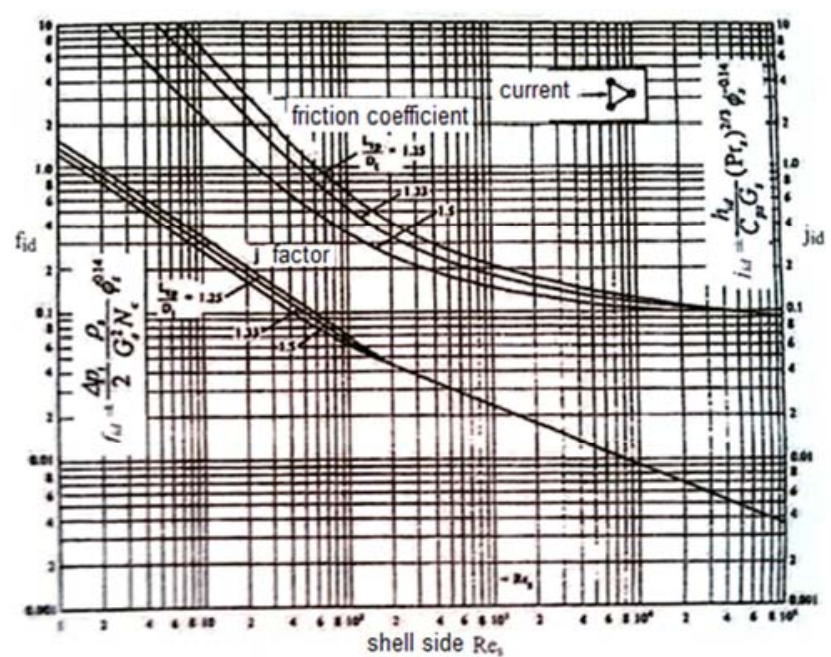

Figure 4. Coefficients of $J_{M}$ and $f_{M}$, set of ideal tube for locating the periodic of 30 degree.

Although ideal amounts of $j_{\text {id }}$ and $f_{i d}$ are provided in the form of a diagram, for calculations and analysis with the help of computer, the set of relations which are obtained from the above diagrams are employed in the following way:

$$
\mathrm{j}_{\mathrm{id}}=a_{1}\left(\frac{1.33}{\frac{P_{T}}{d_{o}}}\right)^{a}\left(R e_{S}\right)^{a_{2}}
$$

in which

$$
\mathrm{a}=\frac{\mathrm{a}_{3}}{1+0.14\left(\operatorname{Re}_{\mathrm{s}}\right)^{\mathrm{a}_{4}}}
$$




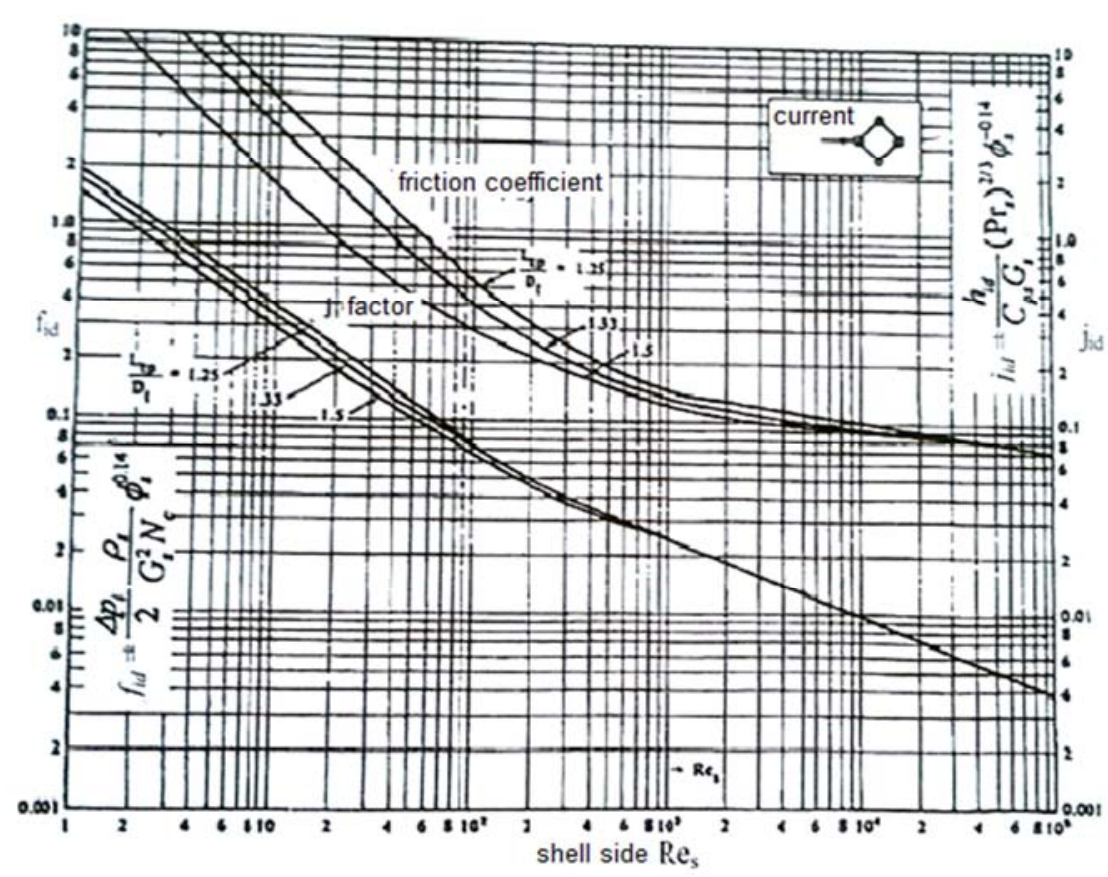

Figure 5. Coefficients of $J_{M}$ and $f_{M}$, set of ideal tube for locating the periodic of 45 degree.

and pressure drop coefficient is:

$$
f_{i d}=b_{1}\left(\frac{1.33}{\frac{P_{T}}{d_{0}}}\right)^{b}\left(\operatorname{Re}_{s}\right)^{b_{2}}
$$

in which

$$
\mathrm{b}=\frac{\mathrm{b}_{3}}{1+0.14\left(\mathrm{Re}_{\mathrm{s}}\right)^{\mathrm{b}_{4}}}
$$

the coefficient of the relations 10 and 11 are provided in table 1.

\begin{tabular}{|c|c|c|c|c|c|c|c|c|c|}
\hline Locating angle & Reynolds number & $a_{1}$ & $a_{2}$ & $a_{3}$ & $a_{4}$ & $\mathrm{~b}_{1}$ & $b_{2}$ & $b_{3}$ & $\mathrm{~b}_{4}$ \\
\hline \multirow[t]{5}{*}{$30^{\circ}$} & $10^{5}-10^{4}$ & 0.321 & -0.388 & 1.450 & 0.519 & 0.372 & -0.123 & 7.00 & 0.500 \\
\hline & $10^{4}-10^{3}$ & 0.321 & -0.388 & & & 0.486 & -0.152 & & \\
\hline & $10^{3}-10^{2}$ & 0.593 & -0.477 & & & 4.570 & -0.476 & & \\
\hline & $10^{2}-10$ & 1.360 & -0.657 & & & 45.100 & -0.973 & & \\
\hline & $<10$ & 1.400 & -0.667 & & & 48.000 & -1.000 & & \\
\hline \multirow[t]{5}{*}{$45^{\circ}$} & $10^{5}-10^{4}$ & 0.370 & -0.396 & 1.930 & 0.500 & 0.303 & -0.126 & 6.59 & 0.520 \\
\hline & $10^{4}-10^{3}$ & 0.370 & -0.396 & & & 0.303 & -0.136 & & \\
\hline & $10^{3}-10^{2}$ & 0.730 & -0.500 & & & 3.500 & -0.476 & & \\
\hline & $10^{2}-10$ & 0.498 & -0.656 & & & 26.200 & -0.913 & & \\
\hline & $<10$ & 1.550 & -0.667 & & & 32.00 & -1.000 & & \\
\hline \multirow[t]{5}{*}{$90^{\circ}$} & $10^{5}-10^{4}$ & 0.370 & -0.395 & 1.187 & 0.370 & 0.391 & -0.148 & 6.30 & 0.378 \\
\hline & $10^{4}-10^{3}$ & 0.107 & -0.266 & & & 0.0815 & +0.022 & & \\
\hline & $10^{3}-10^{2}$ & 0.408 & -0.460 & & & 6.0900 & -0.602 & & \\
\hline & $10^{2-} 10$ & 0.900 & -0.631 & & & 32.10000 & -0.963 & & \\
\hline & 10 & 0.970 & -0.667 & & & 35.0000 & -1.000 & & \\
\hline
\end{tabular}

Table 1. Empirical coefficients for $J_{i}$ and $F_{i}$.

Jc is the correction coefficient for the percentage of partitions cutting and the distance between them. This coefficient of heat transfer at the window site (the area that is cut and separated) should be taken into account and the total heat transfer coefficient should be calculated for the whole heat exchanger. This coefficient is dependent on the shell inner diameter and the distance with the wall (cut height of partition). For a big cutting of the wall, this coefficient may decrease up to 0.53 and for a heat exchanger without any tube at the window site, the amount of this coefficient is about 1 . This coefficient may increase up to 1.15 for small windows with a high speed flow.

$\mathrm{J}_{\ell}$ is the correction coefficient for the effects derived from leakage of partitions, including the leakage among bundle and tube and partition and the leakage between shell and partition (A and E flows). If the wall are near to each other, 
the decrease in leakage flow in comparison with cross flow increases. $\mathrm{J}_{\ell}$ is a function of the total leakage surface ratio for every partition and for cross flow area between neighboring partitions and also the ratio of shell leakage area and partition is the same as the leakage area of partition and tube. The normal amount of $\mathrm{J}_{\ell}$ is between 0.7 and 0.8 .

$\mathrm{J}_{\mathrm{b}}$ is the correction coefficient for the effects of bypass flows at tube bundle that is due to the looseness between the outermost tube of the shell on one hand and the channel created in the tube bundle for making tube passes on the other hand (flows $\mathrm{F}$ and $\mathrm{C}$ ). For a rather small looseness between outermost shell and tube and for the shell with fixed tube sheet is $\mathrm{J}_{\mathrm{b}} \approx 0.90$.

For a shell with floating head and the ability of taking out the head and tube bundle from the shell, need a bigger looseness and $\mathrm{J}_{\mathrm{b}} \approx 0.70$. narrow pieces related to sealing can increase $\mathrm{J}_{\mathrm{b}}$.

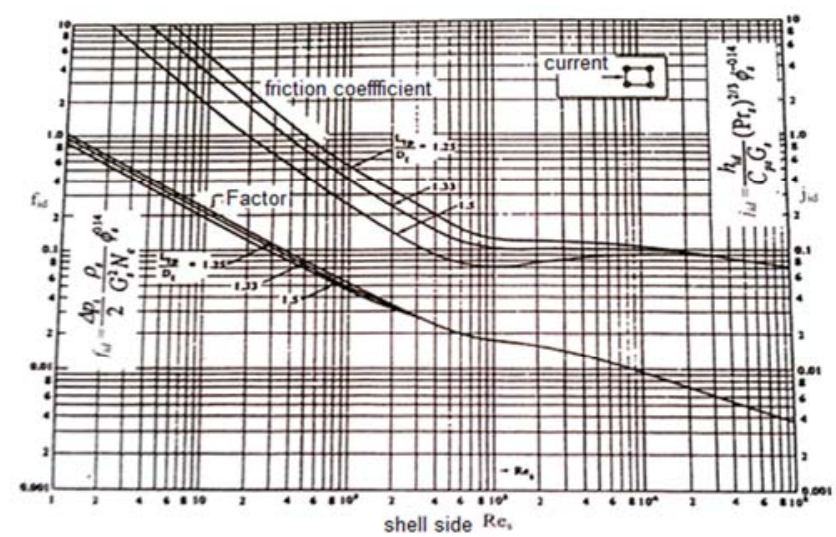

Figure 6. Coefficients of $J_{M}$ and $f_{M}$, set of ideal tube for locating the periodic of 90 degree.

$\mathrm{J}_{\mathrm{S}}$ is the correction coefficient for the changing distance of the walls at the enter and exit of the shell. Due to the more distance of the walls at the nozzle location of exit and enter of the shell and changes in the local speeds in these regions, the average of heat transfer coefficient at the shell side will change. $\mathrm{J}_{\mathrm{S}}$ amount is usually between 0.85 and 1 .

$\mathrm{J}_{\mathrm{r}}$ coefficient is used when Reynolds number in shell side $\operatorname{Re}_{S}$ is less than 100. If $\operatorname{Re}<20$, this factor is completely effective and if $\operatorname{Re}>100$, then $\mathrm{J}_{\mathrm{r}}=1 / 00$.

The mixed influence of all these coefficients for the heat exchanger of the shell and tube kind is 0.60 when the design is perfect.

\subsubsection{Pressure Drop at the Shell Side}

For heat exchanger of the shell and tube kind with by pass and leakage flows, the total pressure drop of the exit nozzle is calculated in the three following ways:

1. Regarding pressure drop of cross flow (in the distance of the two neighboring walls), this pressure drop in the whole shell (except at the two ends) is equal to

$$
\Delta \mathrm{p}_{\mathrm{c}}=\Delta \mathrm{p}_{\mathrm{b} . \mathrm{id}}\left(\mathrm{N}_{\mathrm{b}}-1\right) \mathrm{R}_{\mathrm{b}} \mathrm{R}_{\ell}
$$

where $\Delta \mathrm{P}_{\mathrm{b} \text {,id }}$ is pressure drop at the tube bundle between the two internal partitions (except at the two ends of the exchanger)

$R_{\ell}$ is the correction coefficient for the wall leakage effects (A and $\mathrm{E}$ flows) and it is about 0.4 to 0.5 .

$\mathrm{R}_{\mathrm{b}}$ is the correction coefficient for bypass flows ( $\mathrm{F}$ and $\mathrm{C}$ flows) and it is usually about 0.5 to 0.8 and this parameter is dependent on the structure of thermal exchanger and the number of sealing strips. $\mathrm{N}_{\mathrm{b}}$ is the number of the wall and $\left(\mathrm{N}_{\mathrm{b}}-1\right)$ is number of the distance between internal the wall (except the two ends).

2. Pressure drop at the window is due to the leakage flow but is due to not bypass flow. The whole of pressure drop of the flow from all of window is calculated in the following way:

$$
\Delta \mathrm{p}_{\mathrm{w}}=\mathrm{N}_{\mathrm{b}} \cdot \Delta \mathrm{p}_{\mathrm{w} \cdot \mathrm{id}} \cdot \mathrm{R}_{\ell}
$$

where $\Delta \mathrm{P}_{\mathrm{w}, \text { id }}$ is pressure drop of the flow at one ideal tube bundle at the window section.

3. Pressure drop at the exit and enter areas is affected by bypass flow but is not affected leakage flow. In addition, this pressure drop is also affected by the changing distance of the wall. Pressure drop for exit and enter areas is calculated in the following way:

$$
\Delta \mathrm{p}_{\mathrm{e}}=2 \Delta \mathrm{p}_{\mathrm{b} . \mathrm{id}} \frac{\mathrm{N}_{\mathrm{r} . \mathrm{cc}}+\mathrm{N}_{\mathrm{r} . \mathrm{cw}}}{\mathrm{N}_{\mathrm{r} . \mathrm{cc}}} \mathrm{R}_{\mathrm{b}} \mathrm{R}_{\mathrm{s}}
$$

where $\mathrm{N}_{\mathrm{r}, \mathrm{cc}}$ is the number of rows for cut tubes at the tube bundle by cross flow (the number of cut tubes rows by the any two neighboring walls) and $\mathrm{N}_{\mathrm{r}, \mathrm{cw}}$ is the number of cut tubes rows by cross flow at every wall window.

$R_{S}$ is the correction coefficient for exit and enter areas that due to the exit and enter nozzles have different wall distances with middle walls distances.

the total pressure drop in the thermal exchanger is

$$
\begin{gathered}
\Delta \mathrm{p}_{\mathrm{T}}=\Delta \mathrm{p}_{\mathrm{c}}+\Delta \mathrm{p}_{\mathrm{w}}+\Delta \mathrm{p}_{\mathrm{e}} \\
\Delta \mathrm{p}_{\mathrm{T}}=\left[\left(\mathrm{N}_{\mathrm{b}}-1\right) \Delta \mathrm{p}_{\mathrm{b} . \mathrm{id}} \mathrm{R}_{\mathrm{b}}+\mathrm{N}_{\mathrm{b}} \cdot \Delta \mathrm{p}_{\mathrm{w} . \mathrm{id}}\right] \mathrm{R}_{\ell}+2 \Delta \mathrm{p}_{\mathrm{b} . \mathrm{id}}(1+ \\
\left.\frac{\mathrm{N}_{\mathrm{r} . \mathrm{cw}}}{\mathrm{N}_{\mathrm{r} . \mathrm{cc}}}\right) \mathrm{R}_{\mathrm{b}} \mathrm{R}_{\mathrm{s}}
\end{gathered}
$$

pressure drop in the nozzles should be calculated separately and added to the total pressure drop.

In this equation, $\Delta \mathrm{P}_{\mathrm{b}, \text { id }}$ is calculated in the following way:

$$
\Delta \mathrm{p}_{\mathrm{b} . \mathrm{id}}=4 \mathrm{f}_{\mathrm{id}} \frac{\mathrm{G}_{\mathrm{s}}^{2}}{2 \rho_{\mathrm{s}}}\left(\frac{\mu_{\mathrm{s} . \mathrm{w}}}{\mu_{\mathrm{s}}}\right) \cdot \mathrm{N}_{\mathrm{r} . \mathrm{cc}}
$$

$\Delta \mathrm{P}_{\mathrm{w}, \text { id }}$ for section of the ideal window partition is calculated in the following ways:

when $\mathrm{Re} \geq 100$

$$
\Delta \mathrm{p}_{\mathrm{w} . \mathrm{id}}=\frac{\dot{\mathrm{m}}_{\mathrm{S}}^{2}\left(2+0.6 \mathrm{~N}_{\mathrm{r} . \mathrm{cw}}\right)}{2 \rho_{\mathrm{s}} \mathrm{A}_{\mathrm{o} . \mathrm{cr}} \mathrm{A}_{\mathrm{o.w}}}
$$

and when $\operatorname{Re} \leq 100$

$$
\Delta \mathrm{p}_{\mathrm{w} . \mathrm{id}}=26 \frac{\mu_{\mathrm{s}} \dot{\mathrm{m}}_{\mathrm{s}}}{\sqrt{\mathrm{A}_{\text {o.cr }} \mathrm{A}_{\text {o.w }} \rho_{\mathrm{s}}}}\left(\frac{\mathrm{N}_{\mathrm{r} . \mathrm{cw}}}{\mathrm{P}_{\mathrm{t}}-\mathrm{d}_{\mathrm{o}}}+\frac{\mathrm{B}}{\mathrm{D}_{\text {h.w }}^{2}}\right)+\frac{\dot{\mathrm{m}}_{\mathrm{s}}^{2}}{\mathrm{~A}_{\text {o.cr }} \mathrm{A}_{\text {o.w }} \rho_{\mathrm{s}}}
$$

$\mathrm{D}_{\mathrm{h}, \mathrm{w}}$ is the cross flow surface area from the windows and $\mathrm{A}_{0, \mathrm{~W}}$ and the related correction factors 
$\mathrm{N}_{\mathrm{r}, \mathrm{cc}}$ the number of tube rows that is cut at the tube bundle by cross flow (the number of cut tubes rows by any two neighboring partitions) can be calculated in the following way:

$$
\mathrm{N}_{\mathrm{r} . \mathrm{cc}}=\frac{\mathrm{D}_{\mathrm{s}}\left(1-2 \frac{\ell_{\mathrm{c}}}{\mathrm{D}_{\mathrm{s}}}\right)}{\mathrm{X}_{\ell}}=\frac{\mathrm{D}_{\mathrm{s}}-2 \ell_{\mathrm{c}}}{\mathrm{X}_{\ell}}
$$

where $X_{\ell}$ is defined in the figure 7 and tube pitch is parallel to the flow and can be obtained from table 2 and $\ell_{\mathrm{c}}$ is the height of the wall cut.

$\mathrm{N}_{\mathrm{r}, \mathrm{cw}}$ is the effective number of tube rows in the cross flow in every window and can be calculated from the following equation:

$$
\mathrm{N}_{\mathrm{r} . \mathrm{cw}} \approx \frac{0.8 \ell_{\mathrm{c}}}{\mathrm{x}_{\ell}}
$$

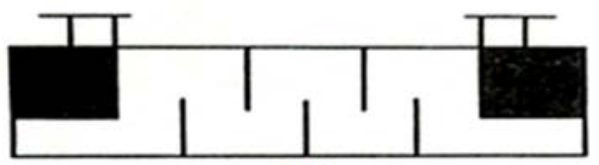

(A)

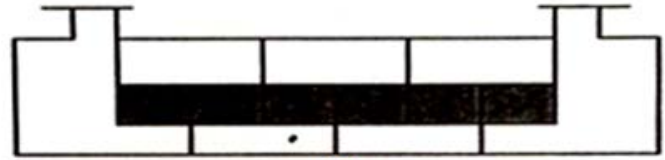

(B)

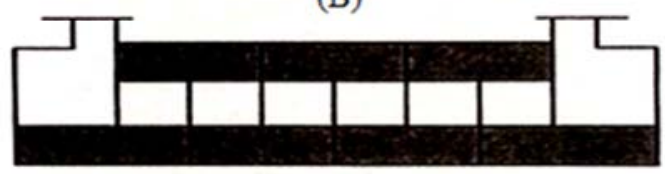

(C)

Figure 7. a) exit and enter areas, b) the distance between walls(except the two ends), c) areas with windows.

the number of walls $\mathrm{N}_{\mathrm{b}}$ can be obtained from the following equation:

$$
\mathrm{N}_{\mathrm{b}}=\frac{\mathrm{L}-\mathrm{L}_{\mathrm{b} . \mathrm{i}}-\mathrm{L}_{\mathrm{b} . \mathrm{o}}}{\mathrm{L}_{\mathrm{b} . \mathrm{c}}}+1
$$

$\mathrm{L}$ is the length of thermal exchanger, and $\mathrm{L}_{\mathrm{b}, \mathrm{i}} \cdot \mathrm{L}_{\mathrm{b}, \mathrm{o}} \cdot \mathrm{L}_{\mathrm{b}, \mathrm{c}}$ are the space of entrance wall, the space of exit wall and the distance between the two interval walls of heat exchanger respectively.

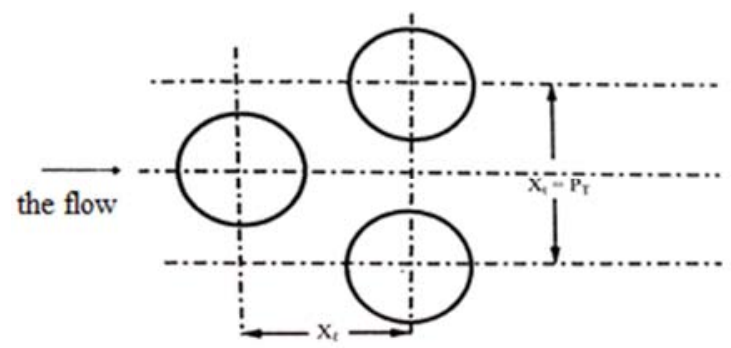

Figure 8. Tube pitches, parallel and upright with the flow. (the arrangement of equilateral triangle).

The pressure drop total at the shell side of shell and tube heat exchanger is about 20 to $30 \%$ of the pressure drop that is calculated ideally without taking the effects of partition leakages flow and the bypass flow of the tube bundle into

\begin{tabular}{|c|c|c|c|c|}
\hline $\begin{array}{l}X_{t} / 2 \text { or } \\
P_{t} / 2 \text { (in) }\end{array}$ & $\mathbf{X}_{\boldsymbol{\ell}}$ (in) & Locating & $\begin{array}{l}P_{t} X_{t \text { or }} \text { Tube } \\
\text { pitch (in) }\end{array}$ & $\begin{array}{l}d_{o} \text { or O.D.outside } \\
\text { diameter tube (in) }\end{array}$ \\
\hline 0.408 & 0.704 & $\rightarrow \lessdot$ & $13 / 16=0.812$ & $5 / 8=0.625$ \\
\hline 0.409 & 0.814 & $\rightarrow \subset$ & $15 / 16=0.938$ & $3 / 4=0.750$ \\
\hline 1.000 & 1.000 & $\rightarrow \square$ & 1.000 & $3 / 4=0.750$ \\
\hline 0.707 & 0.707 & $\rightarrow \diamond$ & 1.000 & $3 / 4=0.75$ \\
\hline 0.500 & 0.866 & $\rightarrow \prec$ & 1.000 & $3 / 4=0.750$ \\
\hline 1.250 & 1.250 & $\longrightarrow \square$ & $11 / 4=1.250$ & 1 \\
\hline 0.884 & 0.884 & $\rightarrow \propto$ & $11 / 4=1.250$ & 1 \\
\hline 0.625 & 1.082 & $\rightarrow \subset$ & $11 / 4=1.250$ & 1 \\
\hline
\end{tabular}
account.

Table 2. Tube pitches, parallel $\left(X_{\ell}\right)$ and upright $\left(X_{\text {tor }} P_{T}\right)$ with the flow line.

The studied sample of shell and tube exchanger is $U$ shape. Its warm fluid is DM Water and is located at the shell and its cool fluid is water that is cooled in the previous process and in conversion with sea water. The aim of designing this exchanger is decreasing water temperature fluid in cooling of sulfur granulation packages. The entrance operational temperatures and pressures at both side of the shell and tube and the physical specifications of the exchanger is available. A summary of these specifications that is necessary for introducing the exchanger is provided in the tables 3 and 4 .

Table 3. Thermal specifications of sulfur granulation package exchanger.

\begin{tabular}{|c|c|c|c|}
\hline $\begin{array}{l}\text { Type of exchanger (rear } \\
\text { head/shell/stationary head) }\end{array}$ & $\mathrm{BEU}$ & Tube number & 38 \\
\hline $\begin{array}{l}\text { The effective area of the } \\
\text { exchanger }\left(m^{2}\right)\end{array}$ & 3.6 & $\begin{array}{l}\text { Tube pitch } \\
(\mathrm{mm})\end{array}$ & 18.36 \\
\hline Shell Outside diameter (mm) & 217.5 & Tube pattern & $30^{\circ}$ \\
\hline Shell Inside diameter (mm) & 201.5 & $\begin{array}{l}\text { Tube pass } \\
\text { numbers }\end{array}$ & 2 \\
\hline Tube inside diameter $(\mathrm{mm})$ & 12 & Baffle type & $\begin{array}{l}\text { single } \\
\text { segmental }\end{array}$ \\
\hline $\begin{array}{l}\text { The thickness of the tube wall } \\
(\mathrm{mm})\end{array}$ & 1.5 & Baffle cut & $\begin{array}{l}33 \% \\
\text { horizontal }\end{array}$ \\
\hline Tube length (mm) & 1300 & $\begin{array}{l}\text { Number of } \\
\text { baffle }\end{array}$ & 9 \\
\hline
\end{tabular}

\begin{tabular}{lll}
\hline Fluid categories & Shell side & Tube side \\
\hline Fluid name & Hot water (system wotking fluid) & Cold water \\
Mass flow $(\mathrm{kg} / \mathrm{h})$ & 27100 & 13800 \\
Temperature (In/Out) $(\mathrm{C})$ & $110.85 \quad 121.5$ & $59 \quad 38$ \\
Pressure (kpa) & 450 & 300 \\
Speed (m/s) & 0.73 & 1.6 \\
Reynolds number & 33328.42 & 25230.8 \\
Pressure drop & 16.53 & 10.48 \\
Heat exchanged (KW) & 337.112 & \\
\hline
\end{tabular}

Table 4. Mechanical specifications of sulfur granulation package exchanger.

\section{Geometrical Production of Exchanger}

For geometrical examined in this study is the use of ASPEN B-JAC software. figures below shows a view of the shell and tube exchangers that in this the software is designed and modeled. 


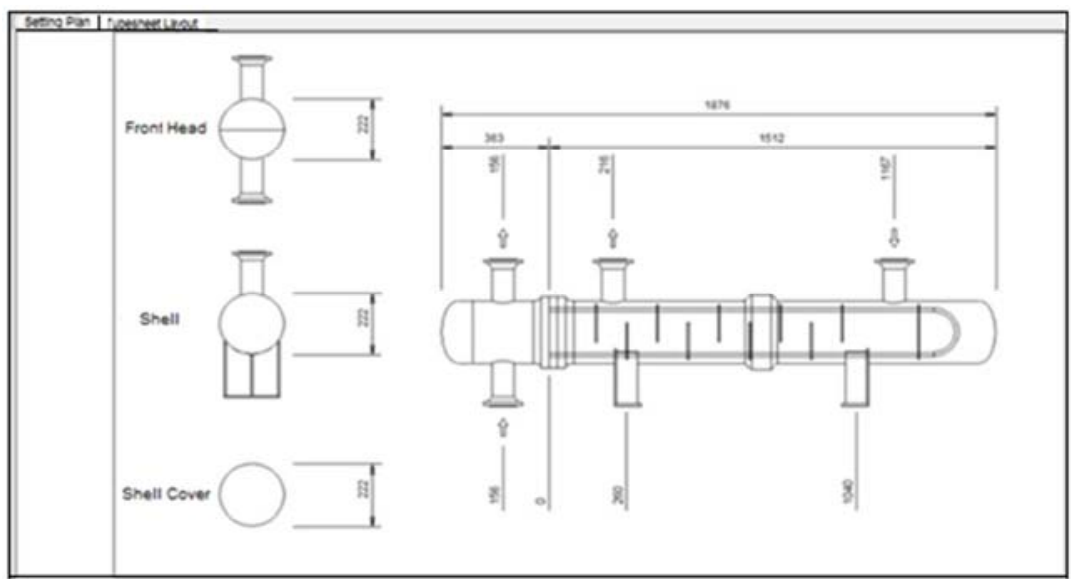

Figure 9. Designing simulated sulfur granulation package exchanger in ASPEN B-JAC software.

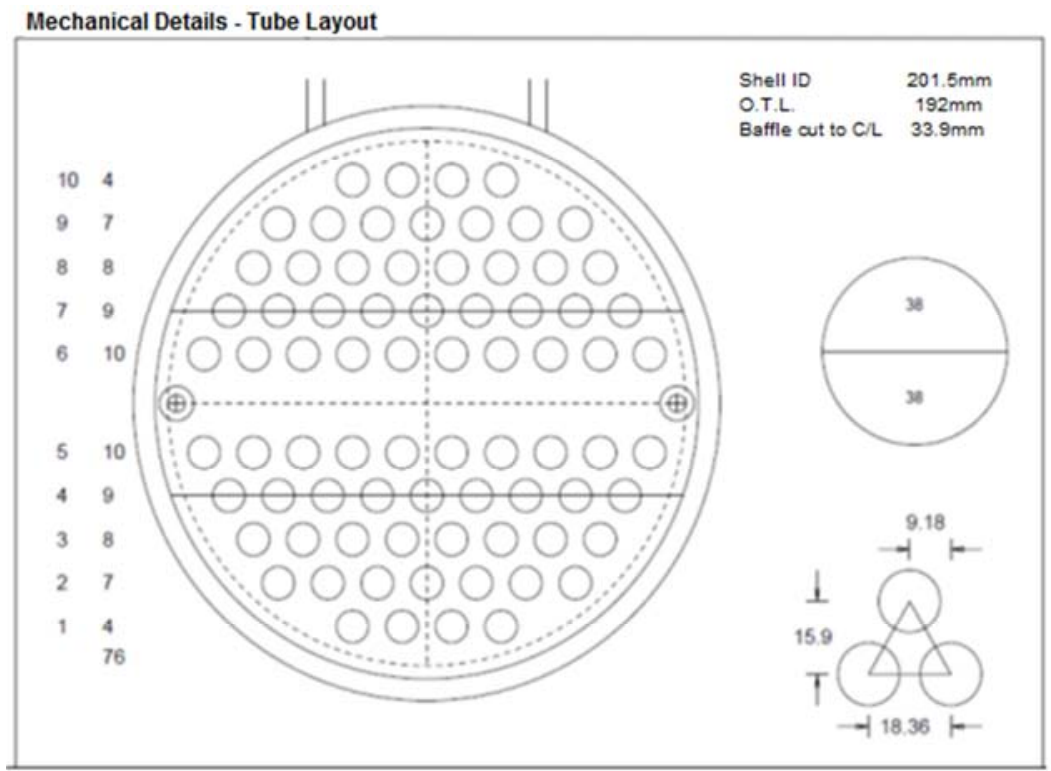

Figure 10. Arrangement of simulated sulfur granulation tube sheet exchanger in ASPEN B-JAC software.

Now, it is the time to run the program. By running the program, at first opened a new folder that shows the software status and calculation status according to figure 10 .

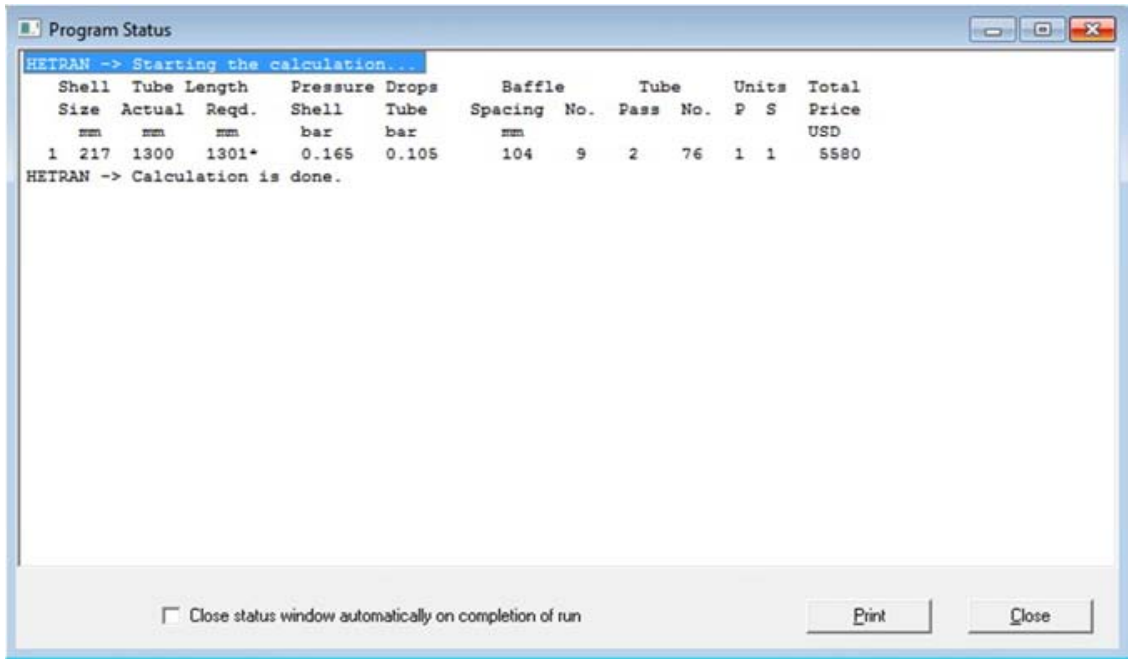

Figure 11. The software status in sulphur granulation exchanger. 


\section{Validating of Software with Observed Realities in the Exploitation Process}

The aim of this chapter is to analyze the validity of the studies with observed realities in the exploitation process. In addition, the mechanical details of the exchanger, such as the number of tubes, arrangement and....should be in agreement with the available plans.

As it is clear in the Figure 9, the arrangement of the tubes in tube sheet of the sulfur granulation package exchanger is as same as available documents in the refinery.

Table 5. Mechanical details of sulfur granulation package exchanger, simulated in the ASPEN software.

Mechanical detail - Bundle

\begin{tabular}{llllll}
\hline Baffle type & & single seg & Shell id - bundle otl clearance & $\mathrm{mm}$ & \\
Inlet spacing & $\mathrm{mm}$ & 259 & Baffle hole - tube od clearance & $\mathrm{mm}$ & 9.52 \\
C-C spacing & $\mathrm{mm}$ & 104 & Shell id - bundle od clearance & $\mathrm{mm}$ & 0.79 \\
Outlet spacing & $\mathrm{mm}$ & 120.2 & Baffle od - bundle otl clearance & $\mathrm{mm}$ & 3.18 \\
Number of baffles & & 9 & Pass partition lane width & $\mathrm{mm}$ & 6.35 \\
Supports & & 1 & Impingement protection & & \\
Baffle cut & hor & $33 \%$ & Sealing strips (pairs) & & \\
Triple segmental intermediate cut & & $\%$ & Outer tube limit & $\mathrm{mm}$ & \\
Double/triple segmental outer cut & & $\%$ & Open distance at top & $\mathrm{mm}$ & 191.9 \\
Baffle thickness & $\mathrm{mm}$ & 6 & Open distance at bottom & $\mathrm{mm}$ & 13.15 \\
Tube length & $\mathrm{mm}$ & 1300 & & & \\
Tubesheet thickness (est.) & $\mathrm{mm}$ & 38 & & & \\
\hline
\end{tabular}

\begin{tabular}{|c|c|c|c|c|c|}
\hline \multicolumn{6}{|c|}{ Mechanical detail-Tubes } \\
\hline Tube length & $\mathrm{mm}$ & 1300 & Tube o.d & $\mathrm{mm}$ & 12 \\
\hline Number of tubes & & 76 & Tube wall thickness & $\mathrm{mm}$ & 1.5 \\
\hline Tube pitch & $\mathrm{mm}$ & 18.36 & Tube wall specification & & ave \\
\hline Tube pattern & & 30 & Tube type & & plain \\
\hline Tube passes & & 2 & Fin height & $\mathrm{mm}$ & \\
\hline Tube pass layout & & Ribbon & Fin thickness & $\mathrm{mm}$ & \\
\hline Tubesheet thickness (est. ) & $\mathrm{mm}$ & 38 & Fin density & $\# / \mathrm{m}$ & \\
\hline Tube-tubesheet joint & & groove/expand & Area ratio $\mathrm{Ao} / \mathrm{Ai}$ & & 1.33 \\
\hline Pass partition lane width & $\mathrm{mm}$ & 12.7 & Twisted tape insert width & $\mathrm{mm}$ & \\
\hline Deviation in tubes/pass & & $\%$ & Twist ratio & & \\
\hline
\end{tabular}

The most important point in validating of simulated exchanger in the ASPEN software is adjusting the external temperature of cool and warm fluid of exchanger with the reality.

As it is clear from Table 6 for sulfur granulation package exchanger, the external temperature of the exchanger is 110 for warm fluid and 59 for cool fluid. these numbers are near to reality. the other point is the amount of exchanged heat in the exchanger that is in accordance with reality for the amount $337 \mathrm{KW}$.

Now, after being sure about the precise of exchanger simulation results in the software, can follow necessary actions for optimizing these exchangers in the following chapter. The process is in the following way: Changed, parameters that are flexible in the tube bundle of mentioned exchanger and analyzing their effects on the heat transfer rate and exchanger efficiency.

Table 6. Technical information sheet of simulated sulphur granulation exchanger in aspen B-JAC software.

Heat Exchanger Specification Sheet

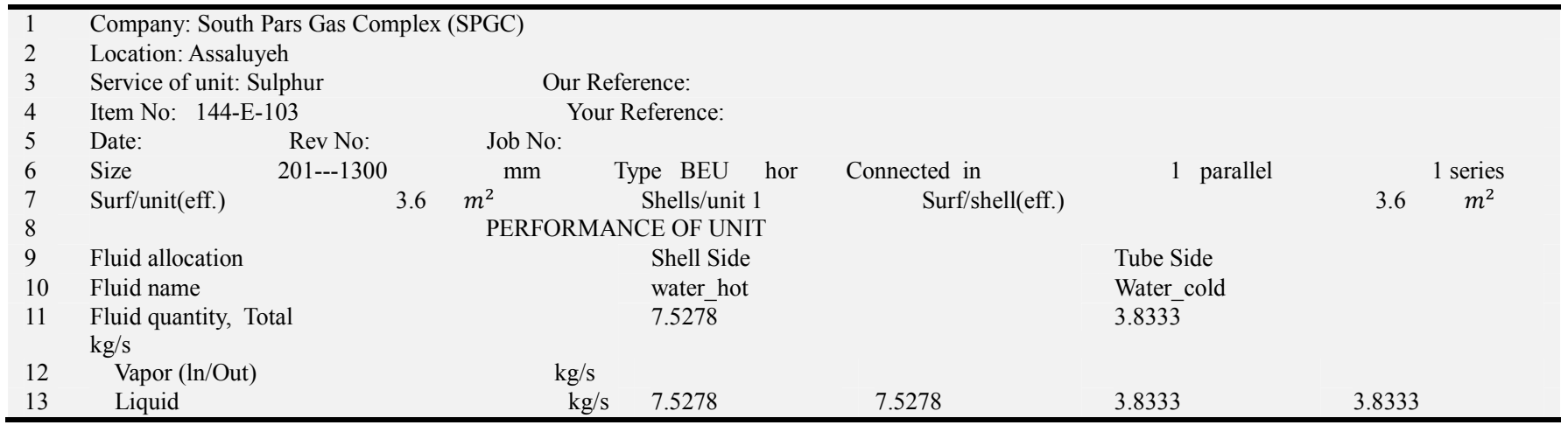




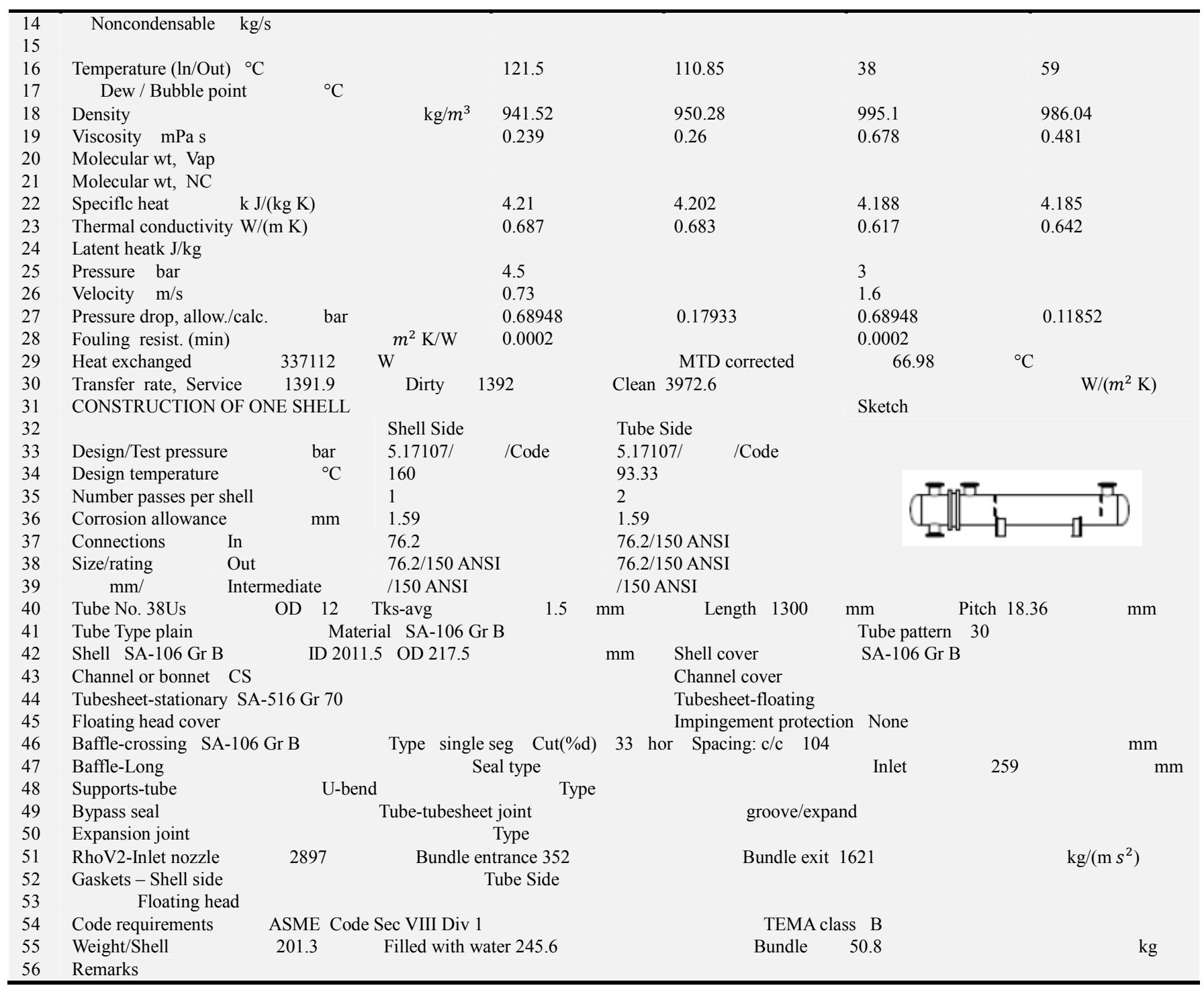

\section{Analyzing Effective Factors on the Efficiency of Sulfur Granulation Package Exchanger}

\subsection{Analyzing the Number of Tube Passes}

In this section, will change the passes of the mentioned exchanger at the tube side. case study (sample of study) has two tube passes. Change in the passes at the tube side will affect thermal rate, pressure drop at the shell and tube side and the speed of the flow at the tube side. It should be mentioned that will decrease the number of tubes to 34 in 4passing state that can be placed in the mentioned shell diameter. So it is not feasible to analyze more than 4 passes due to its shell small diameter. Because decrease in the thermal exchange rate due to decrease in the number of tubes and heat transfer effective level is high.

As figure 12 shows, the thermal rate of 2 passes state is more than other states. while expected that with an increase in passes, two fluids have more opportunity for sharing heat and in line with that heat rate in the four state pass will be more than that of two state pass. But it should be noted that it was our analysis that was not true, not the results of the software. As it was stated, it had to decreased the number of tubes to 34 in 4 state pass that lead to a decrease in heat transfer level and heat rate.

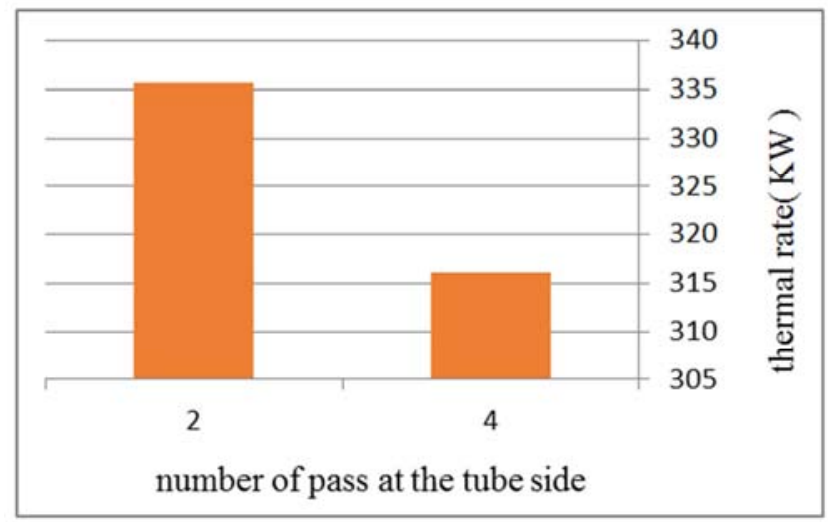

Figure 12. Thermal rate according to the passes at the tube side. 

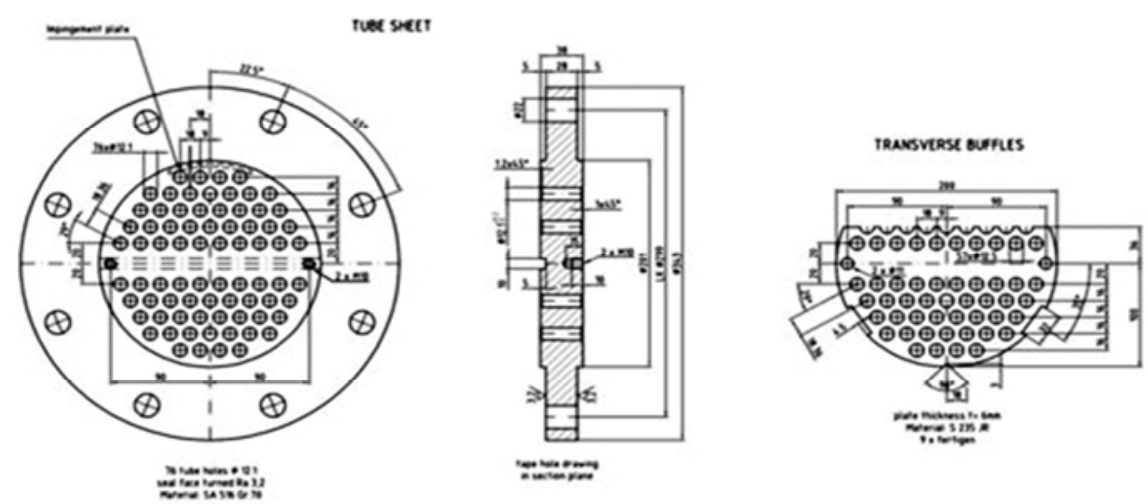

Figure 13. The view from tube sheet and the baffle of sulphur granulation exchanger.

Regarding the Figure 14, can see that pressure drop at the shell side in state of two pass is more than that in other states as it is in the heat rate. With the same reason, with a decrease in the number of tubes, the obstacles around the flow will decrease that lead to a decrease in pressure.

Of course, An increase at the tube passes will lead to an increase in the pressure drop at the shell side, but as it is observable in the four state pass, this increase is less than pressure drop at due to a decrease in the number of tubes.

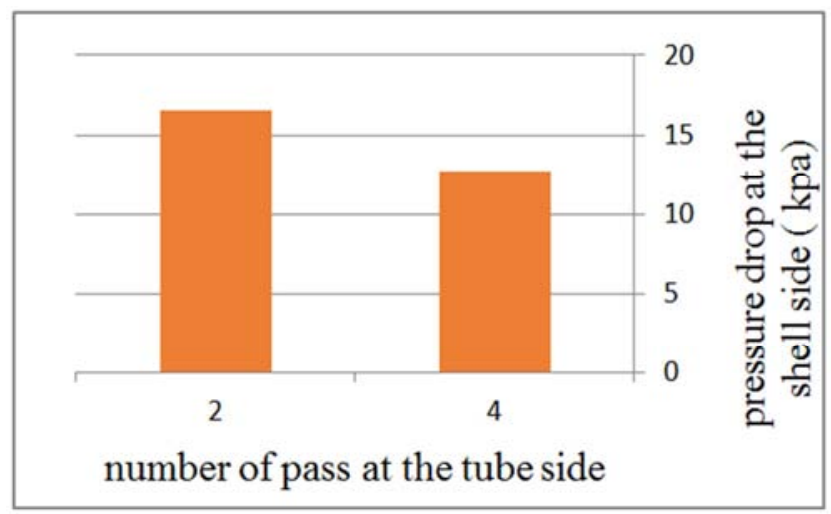

Figure 14. Pressure drop at the shell side according to the passes at the tube side.

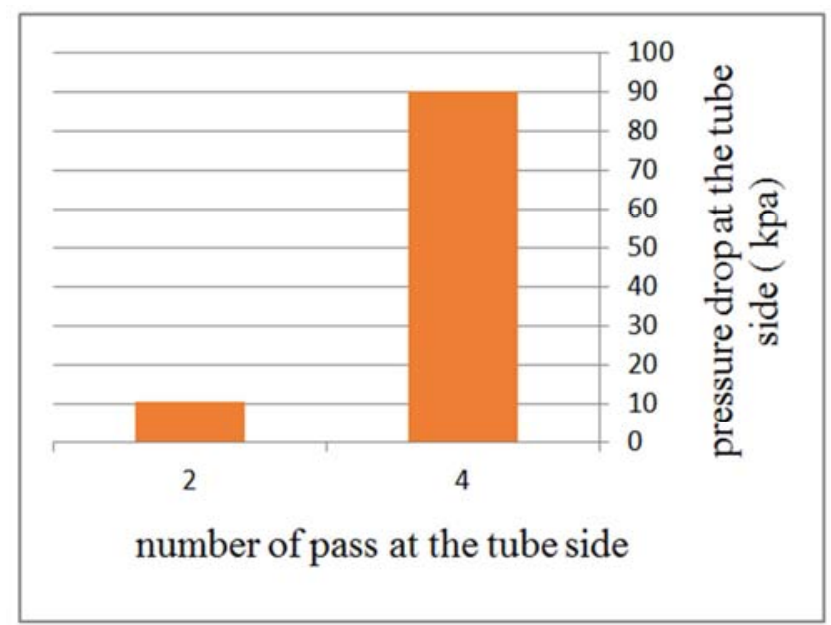

Figure 15. Pressure drop at the tube side according to the passes at the tube side.
Figure 15, indicates that pressure drop at the tube side in four state pass is more than that in other states. an increase in the number of passes will lead to a decrease in the number of available tubes. So, assuming that the mass is instant, flow speed at the tubes will increase. Although this increase of speed will increase, movement coefficient and decrease scaling, but it will lead to increase of pressure drop.

\subsection{Tube Arrangement Analysis}

Table 7 shows the maximum number of embedded tube in 4 arrangement models including the following shapes: triangle (30), rotated triangle (60), square (90) and rotated square (45). In triangle and rotated triangle arrangement, there are more tubes. In addition, triangle arrangement has a higher turbulence and higher heat transfer coefficient and pressure drop, but cannot clean the tubes effectively due to the inappropriate distance for crossing the cleaner.

Table 7. The maximum number of placed pipes in the sulfur granulation exchanger shell according to the tubes pattern.

\begin{tabular}{lllll}
\hline Tube pattern & 30 & 45 & 60 & 90 \\
Number of tube & 38 & 28 & 34 & 32 \\
\hline
\end{tabular}

In table 7 shows the effect of tube arrangement in the exchanged heat. As it is expected, the number of tubes and heat transfer level has direct relation with thermal exchange rate.

In figure 16 showes, Thermal rate based on tubes pattern. as was expected, number of tubes and heat transfer surface has directly proportional with heat exchange rate.

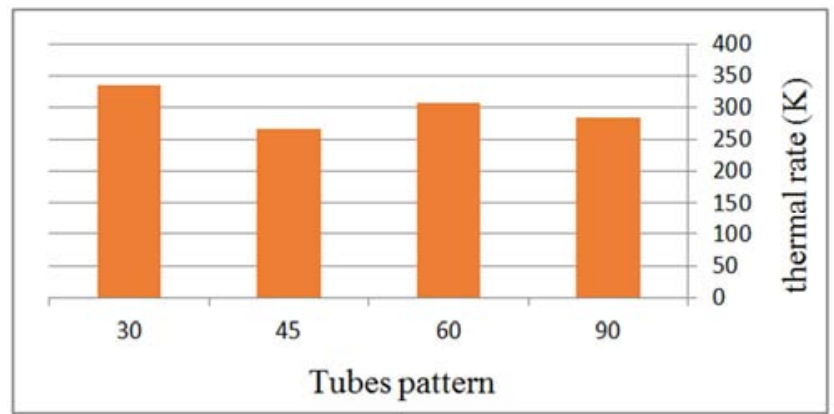

Figure 16. Thermal rate according tubes pattern. 
Based on figure 17, it can be seen that in every arrangement, when the tubes pattern is dense, can have more pressure drop, apart from the increase in the number of tubes in the fixed diameter of the shell. As you see, the higher number of tubes with 90 degree arrangement does not cause its pressure drop to be more than that of 45 degrees. In other words, the effect of tube pattern on pressure drop in 45 degree model is more than the effect of having more tubes in 90 degrees.

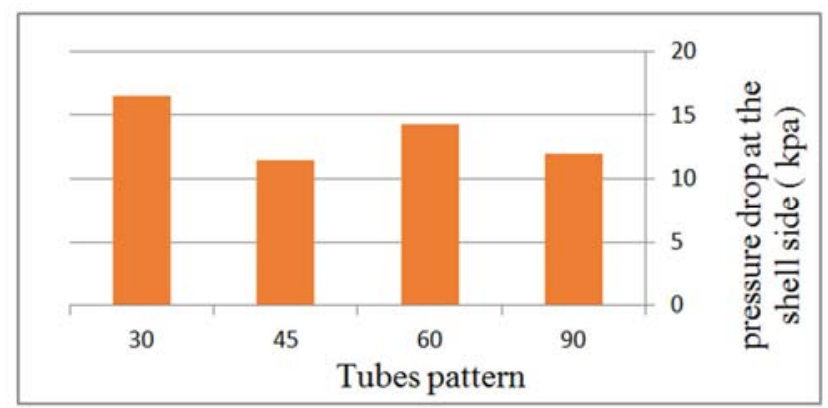

Figure 17. Pressure drop at the shell side according to tubes pattern.

\subsection{Analyzing decrease in tubes pitch}

The important point in analyzing decrease in pitch of tubes of shell and tube exchanger is that, can do the work practically because of the limitation in their connection to the tube sheet and decrease in the bending radius of the tubes. According to the available documents, it can decrease the tube pitch, up to 1.25 of tube outer diameter and this amount should increase for the cases in which tube connection to the tube sheet is of welding kind. Table 8 shows the maximum number of embedded tubes with a decrease in the tubes pitch.

Table 8. The maximum number of embedded tubes in the sulfur granulation exchanger according to the tube pitch.

\begin{tabular}{llll}
\hline Tube pitch $(\mathrm{mm})$ & 16.5 & 17.5 & 18.36 \\
Number of tube & 47 & 40 & 38 \\
\hline
\end{tabular}

In figure 18 , the effect of tubes pitch on exchanged heat rate be shown. As it is expected due to increase in the number of tubes and increase in the heat transfer level, the exchanged heat rate has increased.

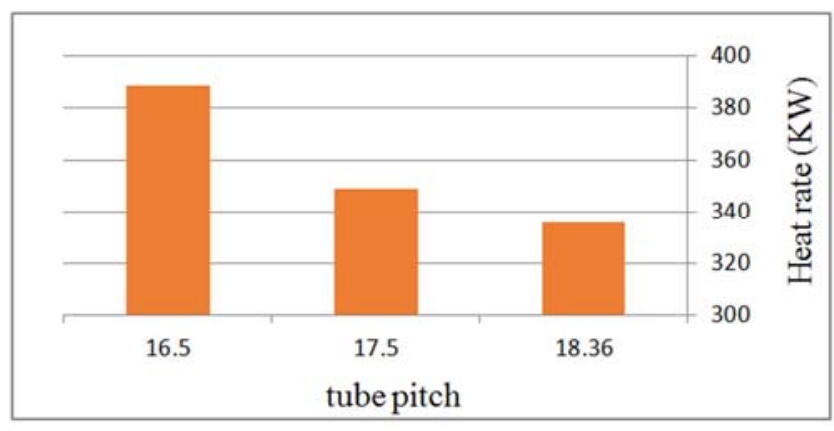

Figure 18. Heat rate based on tube pitch.

In figure 19 and 20, pressure drop due to the tubes pitch decrease at the shell and tube side of exchanger is analyzed and as it is predictable, pressure drop process at the shell side is increasing due to the increase in the number of tubes and it will increase and at the tube side because that the fluid will be able to pass a lot of tubes, will decrease.

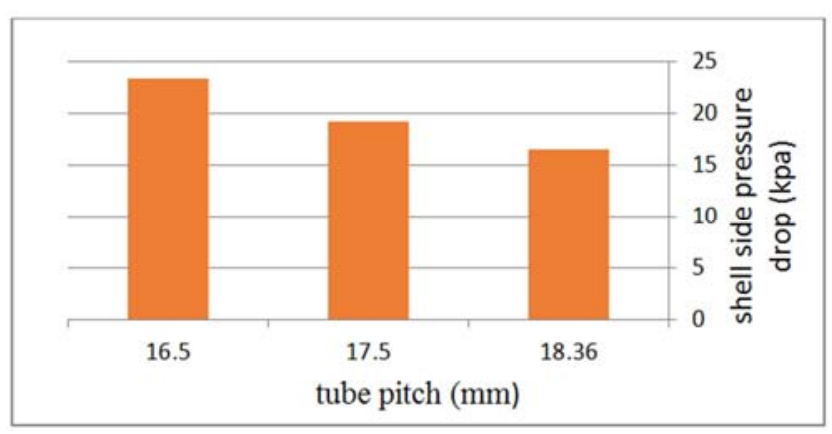

Figure 19. Pressure drop at the shell side according to the tube pitch.

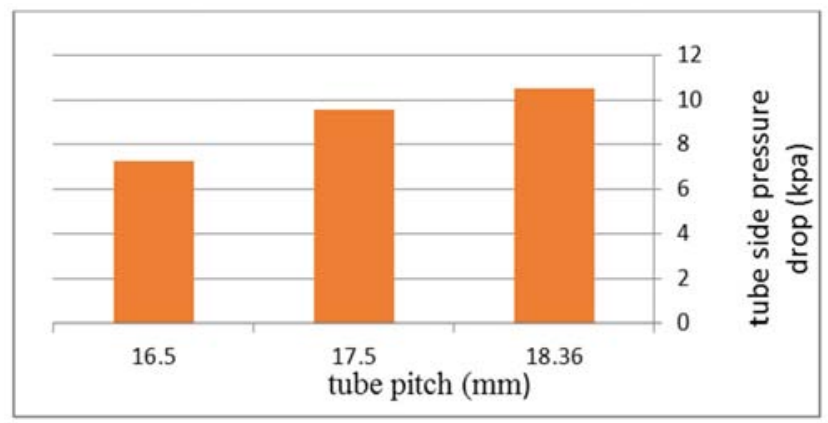

Figure 20. Pressure drop at the tube side according to the tube pitch.

\section{Offers}

It is suggested that take be considered optimizing the other exchangers for refinery due to the large number of exchanger in refinery processes and the necessity of decreasing energy consumption. The important point is that need exact data of the fluids of this process so that can optimize and simulate them with the help of ASPEN B-JAC software. Usually, the fluid in the refinery exchangers consists of several hydrocarbons with different thermal coefficients and evaporation temperatures and different physical specifications that make simulation difficult.

\section{Conclusion}

In this thesis, one exchanger of south pars refineries, phases 9 and 10 was analyzed. The exchanger was sulfur granulation package with the job of adjusting the cooling fluid temperature of these packages. The importance of this exchanger is that not controlling it in an appropriate way can distort in the process of sulfur granulation and the results will be to sulfur burning and damage to the eco-system.

In this study one exchanger of south pars refineries, phases 9 and 10 were investigated. The first exchanger was in the sulfur granulation package which has the function of regulating the temperature of the cooling systems. The importance of these exchanger is due to the fact that the inability in controlling it properly impairs the process of 
sulfur granulation.

With a change in the design of the mentioned thermal exchanger and having proposals according to the table 9 that makes thermal transfer of the two fluids easier, can decrease the necessary energy for cooling this fluid and reduced the cost of pumping the sea water.

The manner in which the choices are made is in this way that consider two pass for optimized exchanger to the permitted pressure drop at the tube side. Arranging the pipes tubes change to 30 degrees, because can use more tubes. And also can decrease the tube pitch from 18.36 up to 16.5 , which causes the placement of more tubes in the exchanger and increases the extent of exchanged heat.

Table 9, shows the comparison of the suggested exchanger with the main model exchanger.

Table 9. The comparison of the suggested exchanger for sulfur granulation package with the main model exchanger.

\begin{tabular}{llll}
\hline & $\begin{array}{l}\text { Main model } \\
\text { exchanger }\end{array}$ & $\begin{array}{l}\text { Suggested } \\
\text { exchanger }\end{array}$ & $\begin{array}{l}\text { Change } \\
\text { percent }\end{array}$ \\
\hline Thermal rate & 1378.762 & 1496.5 & 8.5 \\
Pressure decrease at the shell & 1.765 & 1.505 & -14.73 \\
$\begin{array}{l}\text { Pressure drop at the tube } \\
\text { Maximum number of tubes }\end{array}$ & 12.26 & 18.201 & 48.46 \\
$\begin{array}{l}\text { Placement } \\
\text { Final production cost }\end{array}$ & 56 & 109 & 94.64 \\
\hline
\end{tabular}

\section{Nomenclature}

Latin symbols

$\mathrm{T} \quad$ fluid temperature $(\mathrm{K})$

Q conservative variable vector

he introduced the total energy

$M_{t} \quad$ Mach of turbulent flow

$\mathrm{c}_{\mathrm{p}} \quad$ specific heat $\left(\mathrm{Jkg}^{-1} \mathrm{k}^{-1}\right)$

$\Delta \mathrm{p} \quad$ overall pressure drop $(\mathrm{Pa})$

DT logarithmic mean temperature difference $(\mathrm{K})$

$\mathrm{h}_{\mathrm{O}} \quad$ heat transfer coefficient in the shell side

$\mathrm{D}_{\mathrm{e}} \quad$ the diameter of the shell

$\mathrm{G}_{\mathrm{S}} \quad$ mass speed of shell side

Greek symbols

$\mu \quad$ dynamic viscosity $\left(\mathrm{kgm}^{-1} \mathrm{~s}^{-1}\right)$

$\mu_{\mathrm{t}} \quad$ turbulent dynamic viscosity $\left(\mathrm{kgm}^{-1} \mathrm{~s}^{-1}\right)$

$v_{\mathbf{t}} \quad$ turbulent kinematic viscosity $\left(\mathrm{m}^{2} \mathrm{~s}^{-1}\right)$

$v \quad$ kinematic viscosity $\left(\mathrm{m}^{2} \mathrm{~s}^{-1}\right)$

$\varepsilon \quad$ dissipation rate of turbulent $\left(\mathrm{m}^{2} \mathrm{~s}^{-3}\right)$

$\rho \quad$ density $\left(\mathrm{kg} \mathrm{m}^{-3}\right)$

a speed of sound

$\sigma_{k} \quad$ Prandtl number of $k$

$\sigma_{\varepsilon} \quad$ Prandtl number of $\varepsilon$

$\Omega \quad$ rotation absolute value

$\lambda \quad$ thermal conductivity $\left(\mathrm{Wm}^{-1} \mathrm{k}^{-1}\right)$

Subscripts

In inlet

Out outlet

s shell side

$\mathrm{t}$ tube side

\section{References}

[1] American Society of Mechanical Engineers, (2013), "ASME Boiler and Pressure Vessel Code-An International Code", Section VIII, Division 3, Alternative Rules for Construction of High Pressure Vessels, New York.

[2] Bell,K. J. (1981), Preliminary design of shell and tube heat exchangers. In Heat Exchangers: Thermal-Hydraulic Fundamentals and Design, S. Kaksc, A. E. Bergles, and F. Mayinger (Eds.), Taylor \& Francis, Washington D.C., pp. 559579.

[3] Bell, K. J., (1981), Delaware method for shell-side design. In heat exchangers: Thermal-hydraulic fundamentals and design, S. Kakac, A. E. Bergles, and E. Mayinger (Eds.), pp. 581-618. Taylor \& Francis, Washington D.C.

[4] Fraas, A. P., (1989), Heat Exchanger Design, Wiley, New York.

[5] Gaddis, Daniel, (2007), "Standards of the Tubular Exchanger Manufacturers Association", Tubular Exchanger Manufacturers Association [TEMA], Inc., 9th Edition, New York.

[6] Hewitt, G. F., Shires, G. L., and Bott, T. R., (1994), Process Heat Transfer, CRC Press, Boca Raton, FL.

[7] Sadik Kakac and Hongtan Liu., (2002), Heat Exchanger selection: rating and thermal design book, (2nd ed.). CRC Press.

[8] Saunders, E. A., (1988), Heat Exchanges: Selection, Design and Construction, New York: Longman Scientific and Technical.

[9] Taborek, J., (1983), Shell-and-Tube Heat Exchanger. In Heat Exchanger Design Handbook, E. U. Schlunder (Ed), Section, 3.3. Hemisphere, New York.

[10] Tinker, T., (1951), Shell-side Characteristics of Shell-andTube Heat Exchanger. General Discussion on Heat Transfer, pp. 97-116. Institute Mechanical Engineering and ASME, New York, London.

[11] Holman J. P., 2002. Heat Transfer, 9th Edition, McGraw-Hill.

[12] Hossain, S. N., and Bari, S., (2011), "Effect of different working fluids on shell and tube heat exchanger to recover heat from exhaust of an automotive diesel engine". World Renewable Energy Congress.

[13] Dizaji H. S., Jafarmadar S., Hashemian M., 2015. The effect of flow, thermodynamic and geometrical characteristics on exergy loss in shell and coiled tube heat exchangers, Energy conversion and management, Vol. 91, PP. 678-684.

[14] Gao B., Bi Q., Nie Z. and Wu J., 2015. Experimental study of effects of baffle helix angle on shell-side performance of shelland-tube heat exchangers with discontinuous helical baffles. Experimental thermal and fluid Science, Vol. 68, PP. 48-57.

[15] Yang J. F., Zeng M., Wang Q. W., 2015. Numerical investigation on combined single shell and tube heat exchanger with two-layer continuous helical baffles, International Journal of Heat and Mass transfer, Vol. 84, PP 103-113. 